\title{
Synthesis and properties of novel bis(triarylamines) based on a 3,3'-diphenyl-2,2'-bithiophene core
}

\author{
Ken-Tsung Wong, ${ }^{a} a$ Tsung Hsi Hung, ${ }^{a}$ Shen C. Kao, ${ }^{b}$ Chung Hsien Chou ${ }^{a}$ and Yuhlong Oliver Su ${ }^{a}$ \\ a Department of Chemistry, National Taiwan University, Taipei 106, Taiwan. \\ E-mail: kenwong@ccms.ntu.edu.tw; Fax: +8862 23636359; Tel: +886223630231 ext. 3315 \\ ${ }^{b}$ Advance Instrumentation Center, National Taiwan University, Institute of Organic and Materials, \\ National Taipei University of Technology, Taiwan
}

\section{Received (in Cambridge, UK) 10th April 2001, Accepted 28th June 2001 \\ First published as an Advance Article on the web 3rd August 2001}

\begin{abstract}
An efficient synthesis of 3,3'-diphenyl-2,2'-bithiophene based bis(triarylamines) and their physical properties are reported.
\end{abstract}

Amorphous triarylamines with high glass transition temperatures $\left(T_{\mathrm{g}}\right)$ are widely used as hole-transporting materials in organic light-emitting devices (OLED). ${ }^{1}$ Thiophene and oligothiophene-linked triarylamines and bis(triarylamines), with phenyl rings separating the thiophene system from the terminal diarylamino groups were first introduced by Shirota et $a .^{2}$ These amorphous materials form thin films with high morphological stability and also show interesting hole-transporting properties, resulting in their successful use as colour-tunable emitting materials for OLED devices. Triarylamines with diarylamino group(s) directly attached to thiophene are one of the least exploited class of hole-transporting materials. 3,4 Recently, Watanabe and co-workers ${ }^{5}$ have accomplished a systematical study on Pd-catalysed amination for the synthesis of 2-diarylaminothiophenes and 2,5-bis(diarylamino)thiophenes. In addition to this, a new synthetic strategy involving transition-metal free cyclization followed by thermal decarboxylation has also been introduced for the synthesis of triarylamines bearing a thiophene moiety. ${ }^{6}$ However, the physical properties of thiophene based triarylamines are still limited.5,6 In this communication, we report the synthesis and physical properties of a new class of bis(triarylamines) based on 3,3'diphenyl-2,2'-bithiophene as a central linkage. It is well documented that the physical properties of oligothiophenes and polythiophenes strongly depend on the nature of the substituents. However, the similar oxidation potential and absorption $\lambda_{\max }$ of bithiophene and 3,3'-diphenyl-2,2'-bithiophene have been attributed to counterbalancing the resonance effect of phenyl substituents by the steric effect. ${ }^{7}$ Interestingly, polythiophenes with phenyl substituent(s) at its 3- and 4-position exhibit higher thermal stability and lower oxidation potentials. ${ }^{8}$

$\dagger$ Electronic supplementary information (ESI) available: experimental details and NMR spectra. See http://www.rsc.org/suppdata/cc/b1/ b103194p/
Accordingly, the resulting new class of bis(triarylamines) based on 3,3'-diphenyl-2,2'-bithiophene could enhance the thermal and morphological stability, which are crucial for their application in optoelectronic devices.

$\mathrm{Cu}$-promoted Ullman reaction for the synthesis of $3,3^{\prime}$ diphenyl-2,2'-bithiophene was first reported by Johnson in 1976. ${ }^{9}$ Further synthetic efforts based on the Ni-catalysed Kumada coupling reaction of 2-halo-3-phenylthiophene with 2-magnesium-3-phenylthiophene gave 3,3'-diphenyl-2,2'-bithiophene in poor yields. ${ }^{7,8} \mathrm{We}$ report herein a more efficient synthetic pathway (Scheme 1). In the presence of a catalytic amount of $\operatorname{Pd}\left(\mathrm{PPh}_{3}\right)_{4}, 3,3^{\prime}$-dibromo-2,2'-bithiophene $\mathbf{1}^{10}$ was treated with phenylboronic acid in DME to afford 3,3'diphenyl-2,2'-bithiophene (2) in $86 \%$ yield. Regioselective bromination $^{11}$ of $\mathbf{2}$ was accomplished by treating 2 with bromine in $\mathrm{AcOH}-\mathrm{CHCl}_{3}(1: 2)$ solution, which afforded 5,5'dibromo-3,3'-diphenyl-2,2'-bithiophene $\mathbf{3}$ in $95 \%$ yield. Six different diarylamines were screened to react with 3 respectively in the presence of a catalytic amount of $\operatorname{Pd}(\mathrm{OA}-$ c) ${ }_{2}$ and $\mathrm{PBu}_{3}$ in toluene ${ }^{12}$ at reflux temperature, resulting in compounds $\mathbf{4 a - 4 f}$ as bright yellow solids in moderate yields (Table 1). For a comparative study of the influences of phenyl

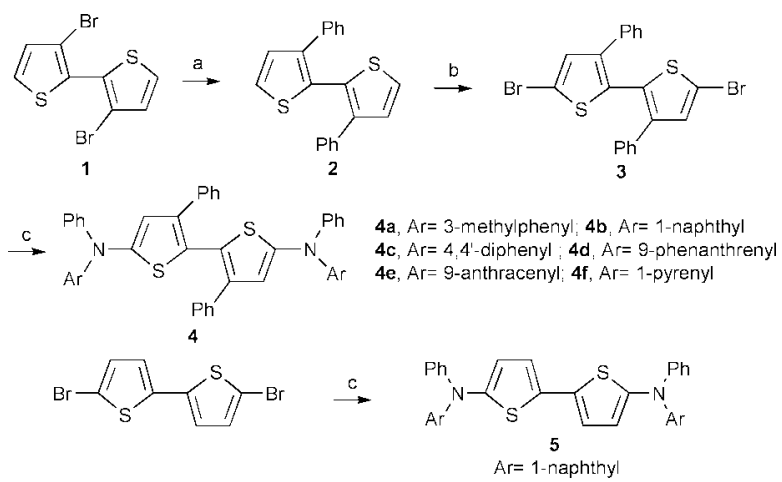

Scheme 1 Reagents and conditions: a, $\mathrm{PhB}(\mathrm{OH})_{2}, \mathrm{Pd}\left(\mathrm{PPh}_{3}\right)_{4}, \mathrm{Na}_{2} \mathrm{CO}_{3}$, DME, reflux $2 \mathrm{~d}, 86 \%$; b, $\mathrm{Br}_{2}, \mathrm{AcOH}-\mathrm{CHCl}_{3}(1: 2), 0{ }^{\circ} \mathrm{C}$ to rt $98 \%$; $\mathrm{c}$, diarylamine, $\mathrm{Pd}(\mathrm{OAc})_{2}, \mathrm{PBu}_{3}{ }_{3}, \mathrm{NaOBu}^{t}$, toluene, reflux overnight.

Table 1 Chemical yields and physical properties of 5,5'-bis(diarylamino)-3,3'-diphenyl-2,2'-bithiophenes 4 and model compound 5

\begin{tabular}{|c|c|c|c|c|c|}
\hline Compound & Yield $(\%)^{a}$ & $\lambda_{\max } / \mathrm{nm}, \log \varepsilon^{b}$ & $\lambda_{\mathrm{em}} / \mathrm{nm}^{c}$ & $E_{\mathrm{pa}}, E_{\mathrm{pc}} / \mathrm{mV}^{d}$ & $T_{\mathrm{g}} /{ }^{\circ} \mathrm{C}^{e}$ \\
\hline $4 \mathbf{a}$ & 62 & 263 (4.59), 367 (4.12) & 535 & 550,430 & 55 \\
\hline $4 b$ & 56 & $262(4.69), 365(4.26)$ & 535 & 595,440 & 85 \\
\hline $4 c$ & 60 & $260(4.96), 317(4.87)$ & 538 & 570,465 & 83 \\
\hline $4 d$ & 52 & $254(4.90), 363(4.09)$ & 539 & 605,470 & 114 \\
\hline $4 e$ & 51 & $256(4.99), 376(4.54)$ & 494 & $(545,455),(650,570)$ & 119 \\
\hline $4 f$ & 53 & $265(4.94), 381(4.48)$ & 458,503 & 600,500 & 124 \\
\hline 5 & 62 & 273 (4.38), $392(4.42)$ & 480 & $(460,385),(695,610)$ & 67 \\
\hline
\end{tabular}

${ }^{a}$ Isolated yield by column chromatography on $\mathrm{SiO}_{2}$ (hexane- $\mathrm{CH}_{2} \mathrm{Cl}_{2}=4: 1$ ) with satisfactory spectral analyses $\left({ }^{1} \mathrm{H},{ }^{13} \mathrm{C}\right.$, mass, $\mathrm{HRMS}$, and IR). ${ }^{b} \mathrm{Recorded}$ in EtOAc; units of $\varepsilon \mathrm{mol}^{-1} \mathrm{dm}^{3} \mathrm{~cm}^{-1}$. ${ }^{c}$ Recorded in EtOAc and excited at $\lambda_{\max }{ }^{d}$ Performed in $0.1 \mathrm{M}$ solution of $\mathrm{n}-\mathrm{Bu}_{4} \mathrm{NPF}_{6}$ in $\mathrm{CH}_{2} \mathrm{Cl}_{2}$, carbon electrode was used as the working electrode, scan rate $100 \mathrm{mV} \mathrm{s}^{-1}, \mathrm{Ag} / \mathrm{AgCl}$ as reference electrode. ${ }^{e}$ Analyzed by differential scanning calorimetry (DSC), $T_{\mathrm{g}}$ was recorded from heating $\left(10{ }^{\circ} \mathrm{C} \mathrm{min}^{-1}\right)$ a liquid nitrogen quenched melt-sample. 


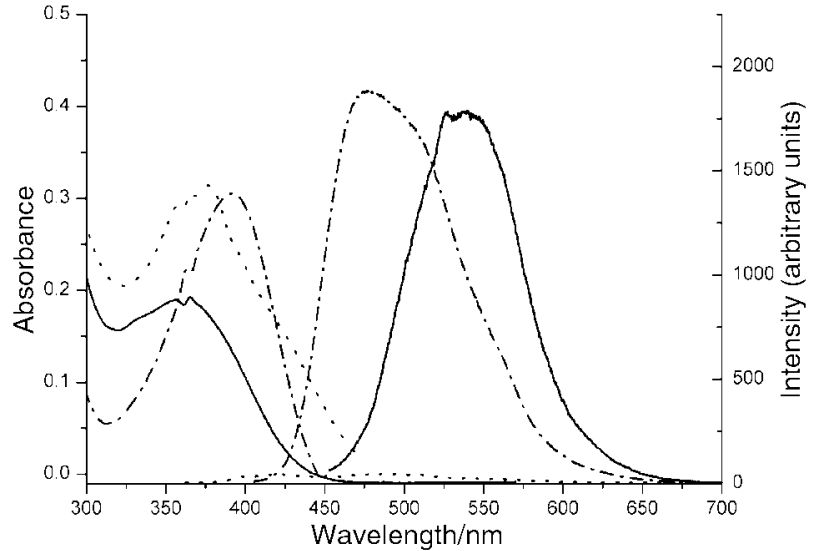

Fig. 1 Absorption and photoluminescence spectra of $\mathbf{4 b}$ (solid), $\mathbf{4 e}$ (dot), and 5 (dash-dot) in EtOAc $\left(1.0 \times 10^{-5} \mathrm{M}\right)$

substituents on the physical properties, model compound $\mathbf{5}$ was also synthesized by the Pd-catalysed amination of $5,5^{\prime}$ dibromo-2,2'-bithiophene.

The absorption spectra of $\mathbf{4 a - 4 f}$ in ethyl acetate showed similar behaviour, displaying two absorption maxima (Table 1). The second bands of $\mathbf{4 e}$ and $\mathbf{4 f}$ were slightly red-shifted compared to that of $\mathbf{4 a - 4 d}$. Compound $\mathbf{4 a}-\mathbf{4 d}$ were highly fluorescent. These results indicate that the absorption $\lambda_{\max }$ is relatively insensitive to the nature of the diarylamino substitutents. However, the photoluminescence efficiency and emission maxima are strongly dependent on the structural feature of the terminal diarylamino groups. Thus, bis(triarylamines) (4a-4d) with less conjugated diarylamino substituents showed more efficient photoluminescence than when compared with those bearing more conjugated terminal diarylamino groups $(\mathbf{4 e}-\mathbf{4 f})$. The significant Stokes shift $(c a .170 \mathrm{~nm}$ for $\mathbf{4 a}-\mathbf{4 d}$ ) reveals that the 3,3'-diphenyl-2,2'-bithiophene linkage may be highly twisted in the ground state. The emission maxima with relatively long wavelength could be attributed to the relaxation from an excited state with a more coplanar conformation. The influence of phenyl substituents of the bithiophene linkage on the photophysical properties are demonstrated by a comparison of the UV-Vis and photoluminescent spectra of $\mathbf{4 b}, \mathbf{4 e}$, and 5 (Fig. 1). Bis(triarylamine) 5 exhibited a sharper, red-shifted absorption and a blue-shifted emission compared to that of $\mathbf{4 b}$. The longer emission wavelength of $\mathbf{4 b}$ further confirms a more conjugated excited state.

Compounds 4a-4f exhibited only quasi-reversible anodic oxidation (Table 1). The onset of oxidation and $E_{\mathrm{pa}}(\mathrm{V} v s . \mathrm{Ag} /$ $\mathrm{AgCl})$ varied with the nature of the terminal diarylamino groups. Differing from the conventional bis(triarylamines), 13 only one redox couple $\left(E_{\mathrm{pa}} 550 \mathrm{mV}, E_{\mathrm{pc}} 430 \mathrm{mV} v s . \mathrm{Ag} / \mathrm{AgCl}\right)$ was detected for $\mathbf{4 a}$ and $\mathbf{4 c}$. Coulometry in a thin layer cell showed the redox process of $\mathbf{4 a}$ to be a two-electron oxidation. The lack of co-planarity of the central 3,3'-diphenyl-2,2'bithiophene linkage prevents the extension of $\pi$-conjugation along the molecular axis. The rate of second oxidation in $\mathbf{4 a}$ may be faster than the conformational change reaching a more coplanar conformation. Therefore, the first radical cation can not efficiently delocalise in the whole molecule, the two triarylamine systems behave independently but are oxidized simultaneously without any communication. Fig. 2 shows a comparison of the cyclic voltammogram of $\mathbf{4 b}, \mathbf{4 e}$, and $\mathbf{5}$. Two partially resolved redox processes $\left(E_{\mathrm{pa}} 545 \mathrm{mV}, E_{\mathrm{pc}} 455 \mathrm{mV}\right.$ and $\left.E_{\mathrm{pa}} 650 \mathrm{mV}, E_{\mathrm{pc}} 570 \mathrm{mV} v s . \mathrm{Ag} / \mathrm{AgCl}\right)$ of $4 \mathrm{e}$ were detected, which were assigned to be a two-step one-electron redox couple corresponding to removal of an electron from each triarylamine system. The redox potential difference $(110 \mathrm{mV})$ of $\mathbf{4 e}$ indicates that the second oxidation could occur via a radical cation with more coplanar conformation. $\mathbf{4 b}, \mathbf{4 d}$, and $\mathbf{4 f}$ showed similar redox behaviour but were less resolved when compared with

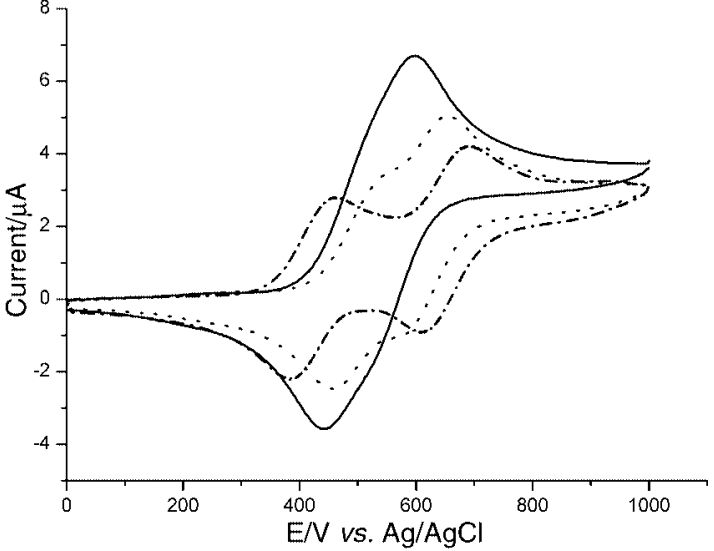

Fig. 2 Cyclic voltammogram of $\mathbf{4 b}$ (solid), $\mathbf{4 e}$ (dot), and $\mathbf{5}$ (dash-dot) in $\mathrm{CH}_{2} \mathrm{Cl}_{2}$

that of 4e. The model compound 5 exhibited two well-resolved redox couples $\left(E_{\mathrm{pa}} 460 \mathrm{mV}, E_{\mathrm{pc}} 385 \mathrm{mV}\right.$ and $E_{\mathrm{pa}} 695 \mathrm{mV}, E_{\mathrm{pc}}$ $610 \mathrm{mV}$ vs. $\mathrm{Ag} / \mathrm{AgCl})$. The lower oxidation onset and larger potential difference $(230 \mathrm{mV})$ reveal that the the central bithiophene linkage is in a coplanar conformation.

All the compounds in this study exhibited an amorphous nature evidenced by the presence of the glass transition temperature (Table 1). The asymmetric diarylamino substituent and the diphenyl substituted central bithiophene linkage significantly contribute to the high $T_{\mathrm{g}} \mathrm{s}$. Compounds $(\mathbf{4 d}, \mathbf{4 e}, \mathbf{4 f})$ with higher molecular weight aryl groups showed higher $T_{\mathrm{g}} \mathrm{s}$ compared to that of $\mathbf{4 a}, \mathbf{4 b}$ and $\mathbf{4 c}$ bearing a lower molecular weight aryl group in the terminal diarylamino substituents.

In summary, we have successfully established an efficient method for the synthesis of a new class of bis(triarylamines) bearing 3,3'-diphenyl-2,2'-bithiophene as a central linkage. The introduction of phenyl substituents on the central linkage apart from improving the morphological stability, twists the conformation of the central bithiophene linkage in the ground state, which results in interesting photophysical and electrochemical properties. Further studies on the modification of the central bithiophene linkage by introducing bulkier aryl groups and their applications in OLED are under way and will be reported in due course.

We thank the National Science Council of Taiwan for providing financial support (NSC-89-2113-M002-053).

\section{Notes and references}

1 C. H. Chen, J. Shi and C. W. Tang, Macromol. Symp., 1997, 125, 1; Y Shirota, J. Mater. Chem., 2000, 10, 1 .

2 T. Noda, I. Imae and Y. Shirota, Adv. Mater., 1997, 9, 239; T. Noda, H. Ogawa, N. Noma and Y. Shirota, Adv. Mater., 1997, 9, 720; T. Noda, H. Ogawa, N. Noma and Y. Shirota, J. Mater. Chem., 1999, 9, 2177.

3 E. Ueta, H. Nakano and Y. Shirota, Chem. Lett., 1994, 2397.

4 I.-Y. Wu, J. T. Lin, Y.-T. Tao and E. Balasubramaniam, Adv. Mater., 2000, 12, 668.

5 M. Watanabe, T. Yamamoto and M. Nishiyama, Chem. Commun., 2000, 133.

6 H. Hartmann, P. Gerstner and D. Rohde, Org. Lett., 2001, 3, 1673.

7 É. Naudin, N. E. Mehdi, C. Soucy, L. Breau and D. Bélanger, Chem. Mater., 2001, 13, 634

8 M. Ueda, T. Ito, Y. Seino, Y. Ohba and T. Sone, Polym. J., 1992, 24 693; R. J. Waltman, A. J. Diaz and J. Bargon, J. Electrochem. Soc., 1984, 131, 740 .

9 A. L. Johnson, J. Org. Chem., 1976, 41, 1320.

10 U. Dahlmann and R. Neidlein, Helv. Chim. Acta, 1996, 79, 755.

11 H. Meng and W. Huang, J. Org. Chem., 2000, 65, 3894.

12 T. Yamamoto, M. Nishiyama and Y. Koie, Tetrahedron Lett., 1998, 39, 2367.

13 B. E. Koene, D. E. Loy and M. E. Thompson, Chem. Mater., 1998, 10, 2235. 